\title{
DFT studies of conversion of methyl chloride and three substituted chloromethyl tetrahydrofuran derivatives during reaction with trimethylamine
}

\author{
Dominik Walczak • Andrzej Nowacki
}

Received: 24 May 2013 / Accepted: 8 July 2013 / Published online: 6 August 2013

(C) The Author(s) 2013. This article is published with open access at Springerlink.com

\begin{abstract}
B3LYP/6-31+G** level computations were performed for the formation of four trimethylammonium salts in the reaction of methyl chloride (1a), (S)-1,4-andydro-5chloro-2,3,5-trideoxypentitol (2a), (2S,5S)-2,5-andydro-6chloro-1,3,4,6-tetradeoxyhexitol (3a) and methyl 5-chloro2,3,5-trideoxy- $\beta$-D-pentofuranoside (4a) with trimethylamine. All the structures were fully optimized in the gas phase, in chloroform and water. In addition, B3LYP/6-311++G** and MPW1K/6-31+ $\mathrm{G}^{* *}$ level calculations were carried out to estimate activation barrier heights in the gas phase. A detailed description of all stationary points is presented, and the conformational behavior of the THF ring is discussed. B3LYP and MPW1K activation barriers indicate the reaction between methyl chloride and trimethylamine to be the fastest, whereas reaction 4 is the slowest one, both in the gas phase and in solvents. THF ring conformation changes were observed for reactions 2 and 3 along the reaction pathway, whereas it was almost unchanged for reaction 4 , in the gas phase. In the case of reactions $\mathbf{2}$ and 3, different shapes of the THF ring were found for the transition state geometry in the gas phase and in water. The ${ }^{5} E \rightarrow E_{4}$ and ${ }^{3} E \rightarrow E_{5}$ conformational changes were observed for reactions $\mathbf{2}$ and $\mathbf{3}$, respectively.
\end{abstract}

Keywords Conformation - DFT calculations - Menshutkin reaction $\cdot$ THF ring

\section{Introduction}

Quaternary ammonium salts (QASs) are formed when a halogen derivative is treated with a tertiary amine. Such a reaction is called the Menshutkin reaction (MR) [1]. This reaction

D. Walczak $\cdot$ A. Nowacki $(\bowtie)$

Faculty of Chemistry, University of Gdańsk, Wita Stwosza 63, 80-952 Gdańsk, Poland

e-mail: anowacki@chem.univ.gda.pl has been used to obtain a wide variety of QASs from different classes of organic compounds, including $N$-glycopyranosyl quaternary salts [2]. In its classic variant the halogen derivatives are used in the MR; however, the halide leaving group can be successfully replaced by a sulfonate ester [3-7].

Detailed experimental studies of the MR have answered the questions regarding both the mechanistic aspects of this reaction and the conditions required for it to occur. In general, three factors have been recognized to play crucial roles for the MR: the nucleophile strength, the leaving group and the solvent polarity. It has been indicated that the barrier height correlates well with the basicity of the attacking ammine: the stronger base the nucleophile is, the lower barrier is found [8]. Castejon et al. compared the activation barriers in the reaction of alkyl bromide and chloride derivatives with the same nucleophile. Their study revealed that the lower barrier is for the former, due to its weaker basicity of the respective anion formed during the reaction. It had been established already by Menshutkin that this reaction strongly depends on the polarity of the solvent employed [1]. In very polar solvents it occurs easily, whereas it is dramatically retarded in non-polar media. This phenomenon is attributed to the stabilization of both the transition state and the ionic products in polar solvents.

As well as experimental investigations, the MR has been subjected to extensive theoretical study [8-20]. All of them concentrated on rather simple models, for instance methyl or ethyl halide was treated with ammonia, trimethylamine or pyridine. On the other hand, examples of theoretical studies of more complex models of the MR are being carried out more and more often. Melo et al. used the B3LYP functional to study the quaternization reaction between 2-amino-1methylbenzimidazole and iodomethane [21]. Fábián et al. presented the mechanism of nucleophilic substitutions at phenacyl bromides with pyridine [22]. Bini et al., in turn, studied the effect of ionic liquids on the MR between $\mathrm{N}$ methylimidazole and benzyl halides [23]. These examples 
indicate that the MR is still an attractive field of investigation, and effort has now turned toward problems more interesting from the organic chemical point of view.

Earlier, we studied the reaction of the formation of ammonium and pyridinium salts starting from sulfonate esters [24-27]. In continuation of our theoretical studies, the results concerning the reaction between trimethylamine and three chloride derivatives are presented herein (Fig. 1). Calculations for the conversion of methyl chloride were also done for comparison.

Constantly, the aim of these studies is to make a thermodynamic and kinetic description of the MR reaction for reactants more complex than those used typically. The present paper is focused on the study of the leaving group exchange effect in the reaction of trimethylamine with chloride derivatives. Moreover, it is intended to check whether, as previously observed, the influence of branching at the reaction center and at the carbon atom three bonds distant from the reaction center (the methyl or methoxy group bound to $\mathrm{C} 5$ of the THF ring is $c i s$-oriented in relation to $\mathrm{C} 1$ ) will also take place in this case.

\section{Methods}

All the calculated structures were prepared in the MOLDEN program [28]. The ground state and the transition state geometries were fully optimized using density functional theory (DFT) based on Becke's three-parameter hybrid exchange [29] functional involving the gradient-corrected correlation functional of Lee, Yang and Parr [30] (B3LYP) with 6-31+ $\mathrm{G}^{* *}$ basis set $[31,32]$. The reactant complex and transition state geometries were also calculated at B3LYP/6-311++G** level $[33,34]$. Activation barrier heights obtained from the B3LYP functional are systematically too low in comparison with experimental values or the results of accurate $a b$ initio calculations $[35,36]$. Thus, reactant complexes and transition states were additionally optimized using the MPW1K/6-31+ $\mathrm{G}^{* *}$ method. It has been proved that this functional (PedrewWang 1-parameter model for kinetics, MPW1K) gives remarkably accurate activation barrier heights $[35,37]$. The optimization was considered satisfactory if the energy difference between optimization cycles was less than $1 \times 10^{-6}$ Hartree and a gradient of $<1 \times 10^{-4}$ a.u. was achieved. The convergence of all the systems studied was checked by harmonic vibrational analysis. No imaginary frequencies were observed for the ground state, and there was only one for the transition state.

Solvent effects were included in the calculations employing the self-consistent reaction field SCRF-PCM solvation model [38]. The reactions were studied in chloroform $(\epsilon=4.9)$ and water ( =78.39) at the B3LYP/6-31+G** level. Implicit solvent calculations imply the generation of a vacuum cavity inside a continuous and homogeneous dielectric field. In the PCM model the solute is placed inside a cavity generated by a series of interlocking atomic spheres. To construct the cavities the UA0 method was used with scale factor alpha $=1.2$ for water and 1.4 for chloroform [19].

All DFT calculations were done with the aid of the Gaussian 03 program [39].

\section{Results and discussion}

General characteristic of the reaction pathway

The studied reactions together with atom numbering order are shown in Scheme 1. The atom numbers presented in Scheme 1 are not compatible with IUPAC recommendations and the names shown in Fig. 1, but they were used in this paper to make the presentation of results clearer.

The steps of the reactions under consideration are analogous to those discussed in detail elsewhere [24-27]. In brief, when two separated reactants (denoted as $\mathbf{R}$, electrophile - chloride derivative, and nucleophile - trimethylamine) approach one another a van der Waals complex (RC) is formed. This complex undergoes conversion into an ion pair (IP), passing through the $\mathrm{S}_{\mathrm{N}} 2$ saddle point structure (TS). Next, the ion pair constituents are moved to an infinitely great distance (P) from one another.

Gas phase and solvent calculations for reaction 1

In order to establish a point of reference, first the potential energy surface (PES) and free energy surface (FES) of the reaction between trimethylamine and methyl chloride was explored and characterized in the gas phase and in two solvents (chloroform and water). The results of B3LYP/6-31+G** level geometry searches are presented in Table 1 and in Fig. 2. In addition, Table 1 shows energy barriers calculated at B3LYP/6$311+\mathrm{G}^{* *}$ and MPW1K/6-31+G** levels. The energies were corrected with zero-point vibrational energy (ZPVE). A scaling
Fig. 1 Structures of chloride derivatives converted into trimethylammonium salts

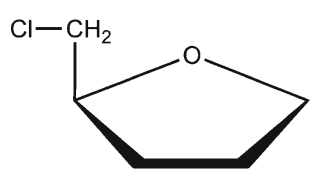

(S)-1,4-anhydro-5-chloro-2,3,5-trideoxypentitol (1a)

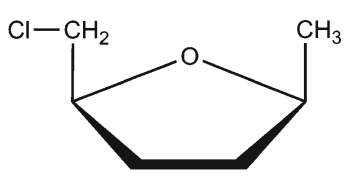

$(2 S, 5 S)$-2,5-anhydro-6-chloro-1,3,4,6-tetradeoxyhexitol (2a)

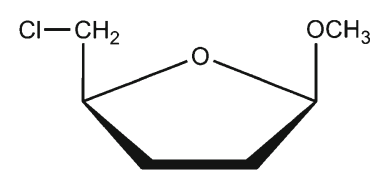

methyl 5-chloro-2,3,5-trideoxy- -D-pentofuranoside (3a) 
Scheme 1 Reactions of trimethylammonium salts formation

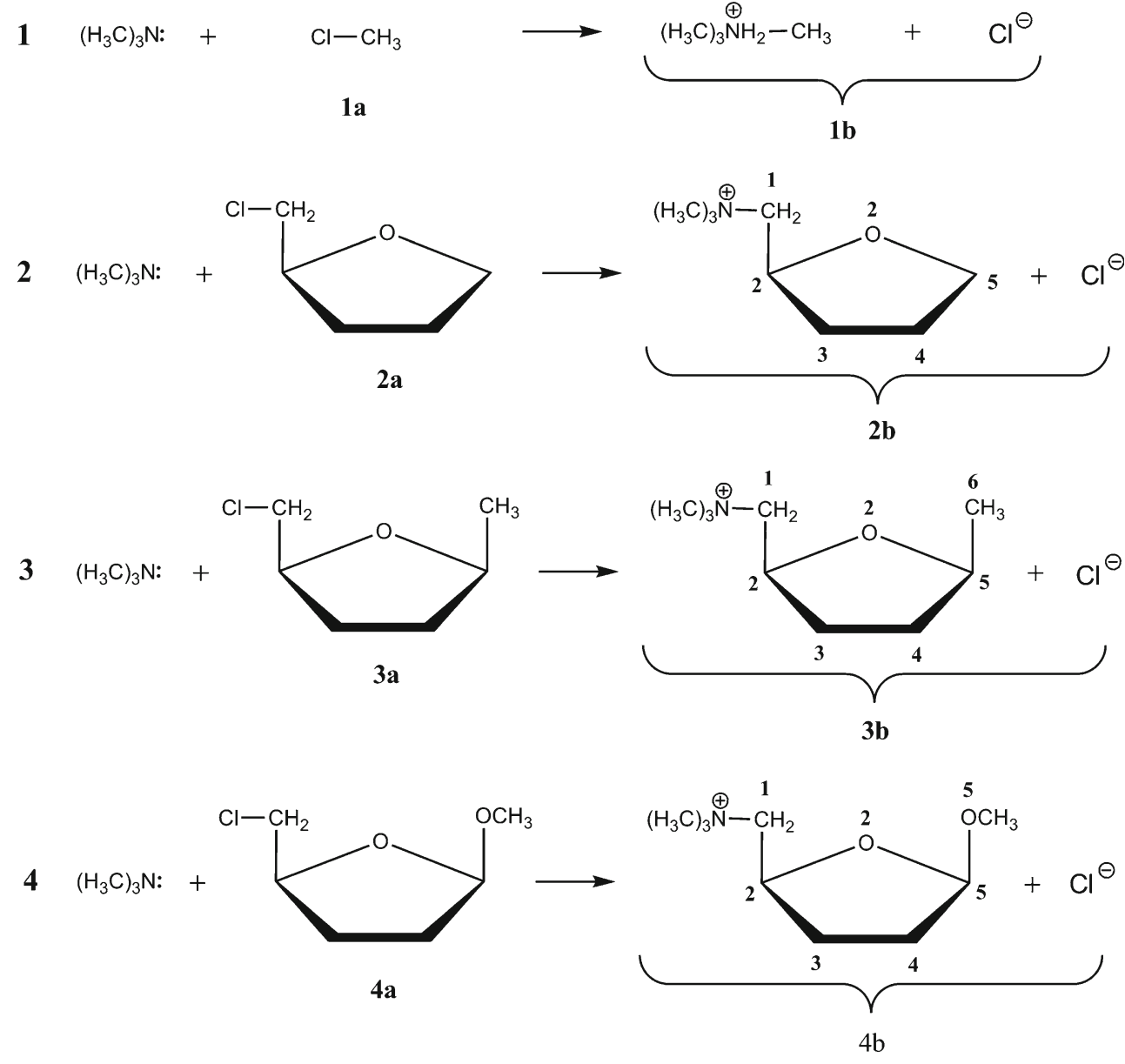

factor of 0.9877 was used to correct for the well-known systematic error in the vibrational zero point energy [40].To estimate the energetics of the reactions studied in solvents a pseudochemical potential $\left(U_{0}\right)$ [41] and Gibbs free energy $(G)$ were used.

The first step of the reaction between methyl chloride and trimethylamine consists of the formation of the moleculepair of reactants (the reactant complex). According to the B3LYP functional, the constituents of the reactant complex are oriented to one another in such a way that the whole geometry has $C_{S}$ symmetry (Fig. 2). This reactant complex is only slightly more stable than the separated reactants $\left(\Delta E=-1.3 \mathrm{kcal} \mathrm{mol}^{-1}\right)$ in the gas phase. An almost identical value was obtained for the reaction between trimethylamine and methyl mesylate [24] and by Castejon et al. [8]. On the other hand, the Gibbs free energy predicts the complexation process to be unfavorable (5.2 $\mathrm{kcal} \mathrm{mol}^{-1}$, Table 1). Similar results are found for this reaction taking place in solvents; the relative Gibbs free energy change suggests the reactant complex formation to be unfavorable.

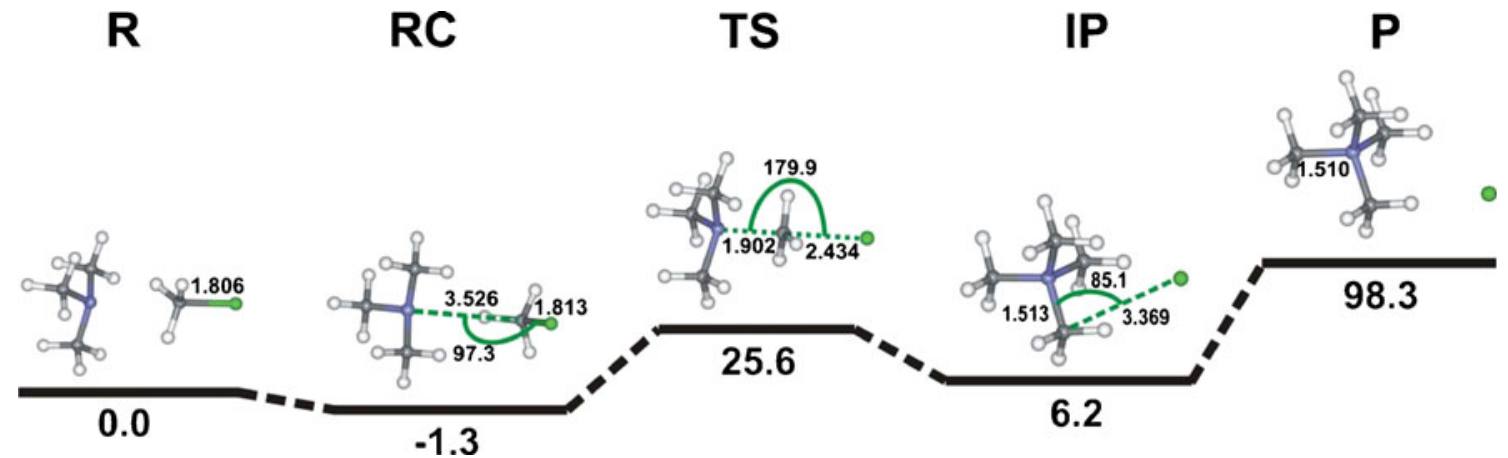

Fig. 2 Geometries and $\Delta E_{0}\left(\mathrm{kcal} \mathrm{mol}^{-1}\right)$ computed at the B3LYP/6-31+G** level presenting the conversion of methyl chloride under trimethylamine action in the gas phase. Selected distances are in $\AA$, and angles are in degrees 


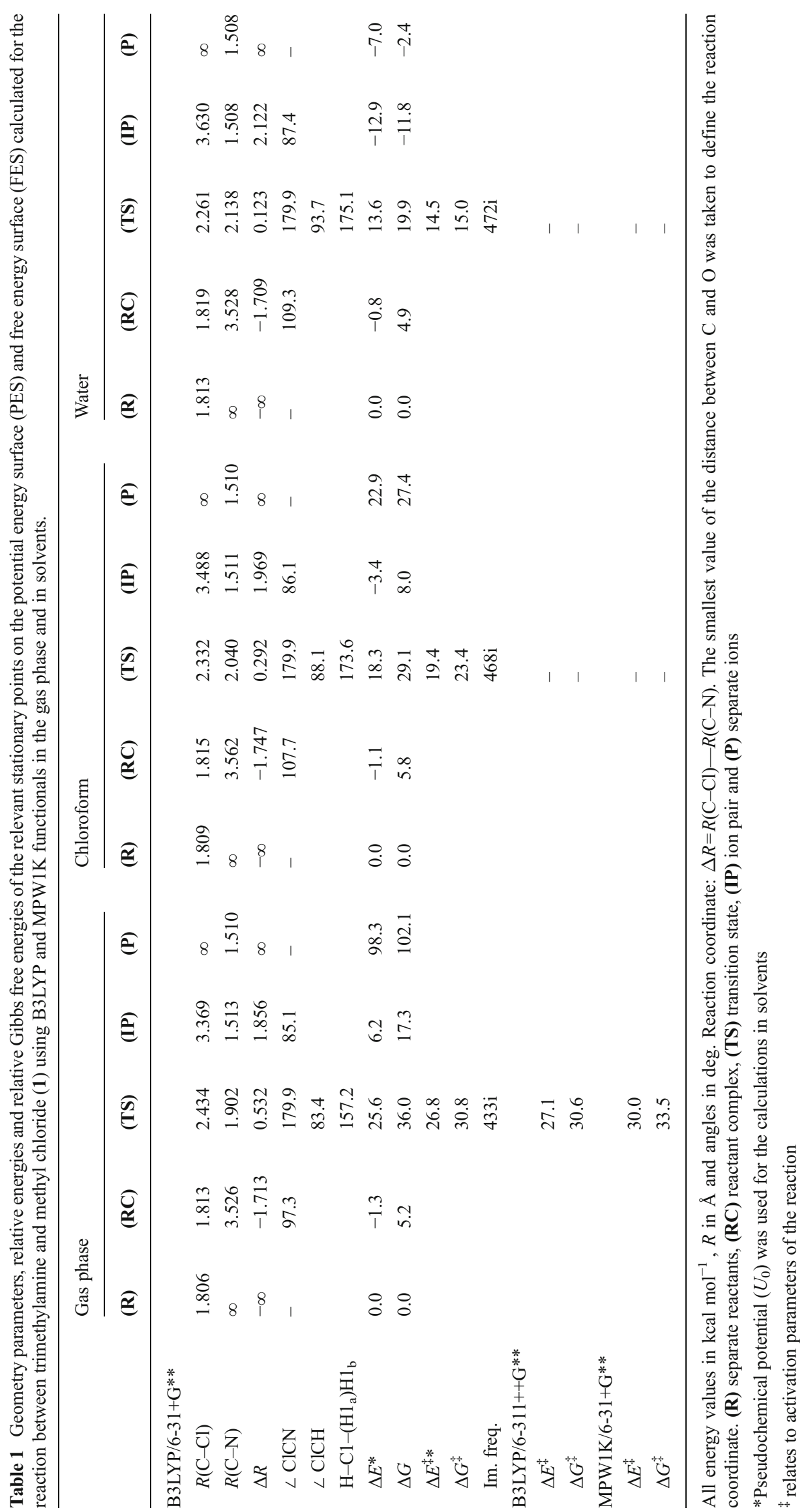


The transition state geometry calculated for this reaction is presented in Fig. 2 and described in Table 1. The value of the $\mathrm{H}-\mathrm{C}-\mathrm{Cl}$ valence angle $\left(83.4^{\circ}\right)$ indicates that the methyl group has partially undergone Walden inversion of the hydrogen atoms at $\mathrm{C} 1$. The same conclusion can be drawn from analysis of the deformation angle $\left(\mathrm{H}-\mathrm{C} 1-\mathrm{H} 1_{\mathrm{a}}-\mathrm{H} 1_{\mathrm{b}}\right.$, Table 1). This angle shows whether the ligands attached to the reaction center carbon are in plane or not in the transition state geometry. For the ideal $\mathrm{S}_{\mathrm{N}} 2$ transition state this angle should be close to $180^{\circ}$. Any deviation from this value indicates the pyramidal disposition of the substituents attached to the $\mathrm{C} 1$ in the transition state geometry. In turn, the sign of this angle indicates whether Walden inversion of the ligands bonded to the reaction center carbon atom has occurred. According to the proposed convention presented in Fig. 3 a negative value means that the ligands are before Walden inversion, whereas the positive value means that the inversion has been done. As a result, this angle gives information about the early/late character of the transition state.

Both the $\mathrm{H}-\mathrm{C}-\mathrm{Cl}$ valence and the deformation angles clearly indicate the late transition state for this reaction in the gas phase. In water the transition state has been shifted to an earlier stage of the reaction with respect to the gas phase, which is revealed from the cited angles and also making/breaking bond inspection. The optimization in solvent yielded considerably longer $\mathrm{C}-\mathrm{N}$ bond length (1.90 and 2.21 $\AA$ for the gas phase and water, respectively) and smaller $\mathrm{C}-\mathrm{Cl}$ bond length (2.43 and $2.21 \AA$ for the gas phase and water, respectively).

The gas phase barrier $\left(\Delta E^{\star}=26.9 \mathrm{kcal} \mathrm{mol}^{-1}\right)$ calculated for this reaction is about $1.6 \mathrm{kcal} \mathrm{mol}^{-1}$ higher than that for the reaction between trimethylamine and methyl mesylate [24]. On the other hand, this barrier is lower than the one obtained by Castejon et al. [8], which corresponds well with the basicity of amines in the gas phase: trimethylamine $>$ pyridine $>$ ammonia [42]. The energy barrier calculated using the MPW1K functional is predicted $\left(\Delta E^{*}\right.$ and $\left.\Delta G^{\star}\right)$ to be about $3 \mathrm{kcal} \mathrm{mol}^{-1}$ higher than those from the B3LYP one in the gas phase. As expected, the barrier height is strongly decreased in solvents. In chloroform, the barrier is about $8 \mathrm{kcal} \mathrm{mol}^{-1}$ lower than in the gas phase. Additional reduction of the barrier height is observed in water.

The ion-pair product has $C_{3 v}$ symmetry with the chloride anion equally distant from three methyl groups

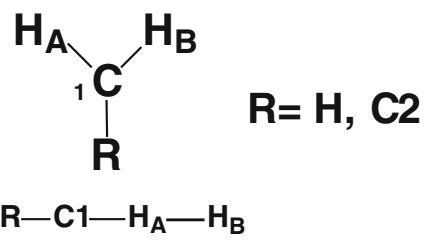

the view from the leaving group side

Fig. 3 Definition of the deformation angle of the tetramethylammonium cation (Fig. 2). The conversion of the reactant complex into the ion-pair product is accompanied by moderate $\left(\Delta E=7.5 \mathrm{kcal} \mathrm{mol}^{-1}\right)$ and strong $\left(\Delta G=12.1 \mathrm{kcal} \mathrm{mol}^{-1}\right)$ energy increase in the gas phase. It is in agreement with the results of Castejon, who stated that ion pair formation is unfavorable in a vacuum [8]. It has been shown previously that this step of the reaction is slightly exothermic when the OMs group is substituted by trimethylamine [24]. Probably, this is because of the greater possibility of charge delocalization within the released mesylate anion.

The decrease in energy is observed for the ion pair formation in solvents. In chloroform this step of the reaction is still unfavorable; however, it is favorable in the water medium. The ion pair energy $(\Delta G)$ is by about $16 \mathrm{kcal} \mathrm{mol}^{-1}$ lower than the reactant complex. Interestingly, the ion pair corresponding to reaction $\mathbf{1}$ appeared to be a real minimum in the condensed phase, in contrast to the literature reports.

The final step of the reaction, i.e., separation of the constituents of the ion pair, requires a great amount of the energy to be supplied in the gas phase. This process is even more difficult than the analogous reaction of the same nucleophile with methyl mesylate [24]. Gibbs free energy to the amount of about $20 \mathrm{kcal} \mathrm{mol}^{-1}$ must be added to the system to dissociate the ion pair in chloroform. In turn, in water this process is much easier; however, the energy is still required to move the ions to an infinite distance apart, according to $\mathrm{PCM} / \mathrm{B} 3 \mathrm{LYP} / 6-31+\mathrm{G}^{* *}$ theory level calculations.

Gas phase calculations of reactions 2,3 and 4

\section{Exocyclic groups conformation}

To analyze the conformational freedom of the chloromethyl group the energy diagram for the rotation about $\mathrm{C} 1-\mathrm{C} 2$ bond has been calculated (Fig. 4) for separate chloride derivatives at the HF/6-31G level. We choose this method since it is able to generate reliable enough results in short time. In all three cases the lowest energy has the $-s c$ rotamer, in which the chloride atom is in antiperiplanar orientation with respect to the ring oxygen atom. We use this rotamer as a starting geometry for the subsequent calculations at higher level of theory.

In reaction 4 the rotation freedom about the $\mathrm{C} 5-\mathrm{O} 5$ bond has to be taken into account. From among three possible orientations of the $\mathrm{OCH}_{3}$ group (Fig. 5) the $-s c$ arrangement is preferred, which can be rationalized based on the steric and exo-anomeric effect, characteristic in glycosides. The exoanomeric effect requires one of the glycosidic oxygen atom lone pair of electrons to be in antiperiplanar position with respect to the endocyclic oxygen atom. This requirement is satisfied in $+s c$ conformation too; however, this orientation suffers strong steric strains and therefore is unfavorable. 


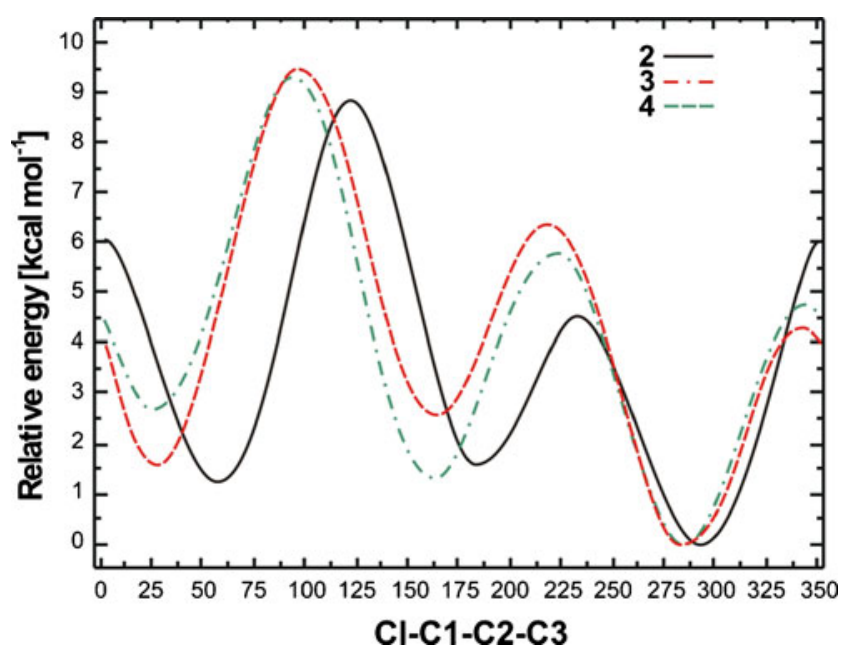

Fig. 4 Energy diagram for the rotation about the $\mathrm{C} 1-\mathrm{C} 2$ bond in separated chloride, calculated at the HF/6-31G level for reactions 2-4

Consequently, the $\mathrm{OCH}_{3}$ group is kept in the $-s c$ orientation in subsequent calculations.

\section{THF ring conformation}

The Altona-Sundaralingam (AS) pseudorotational phase angle $(P)$ and the AS puckering amplitude $\left(\phi_{\mathrm{m}}\right)$ parameters [43, 44] enabled us to describe the conformational changes of the THF ring along the reaction pathway. The THF ring conformation designations, $P$ and $\phi_{\mathrm{m}}$ values found for the most stable ring shapes, are given in Table 2 together with the set of the endocyclic torsion angles $\phi_{0}-\phi_{4}$. The definition of these angles is shown in Fig. 6. The conformational descriptors adopted in this paper differ from the classical ones due to the different atom numbering scheme. Table 2 also lists two torsion angles $(\chi)$ describing the spatial disposition of the exocyclic groups attached to the THF ring.

In reaction 2 the THF ring of the separate chloride derivative takes the conformation lying between $E_{4}$ and ${ }^{3} T_{4}$ $\left(P=352^{\circ}, \phi_{\mathrm{m}}=36^{\circ}\right.$, Table 2$)$, and it does not change when trimethylamine is approaching it forming the reactant complex. The preference of this conformation can be rationalized by the lack of ecliptically oriented substituents, causing unfavorable torsion interactions, and the pseudo-equatorial position of the chloromethyl group $\left(\chi_{1}=-145.2^{\circ}\right)$. Due to such a

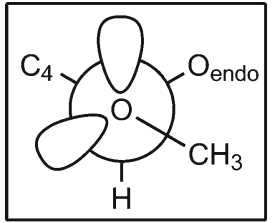

$-S C$

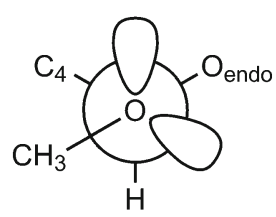

$a p$

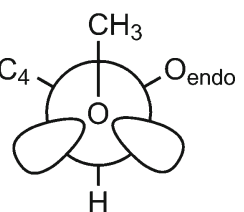

$+s c$
Fig. 5 Rotamers exhibiting possible spatial arrangements of the $\mathrm{OCH}_{3}$ group in relation to the endocyclic oxygen atom. The preferred orientation is in the box spatial disposition of the chloromethyl group the THF ring is free of 1,3-diaxial-like steric interactions. A different conformation is found in the transition state geometry. Here the preferred conformation of the THF ring is ${ }^{5} E\left(P=310^{\circ}\right.$, $\phi_{\mathrm{m}}=37^{\circ}$ ). Another conformational change is observed on going downhill from the transition state to the ion pair product. The ${ }^{3} E$ conformation is preferred at this stage. In fact, this conformation is similar to that found for the reactant complex. Both these conformations lie on the north pole of the pseudorotational circle. In ${ }^{3} E$ conformation the $\mathrm{C} 1$ atom is moved far from the THF ring, $\chi_{1}=-157.2^{\circ}$ therefore making it free of steric hindrance. The same conformation is adopted by the THF ring in free cation.

A more complicated situation is in reaction 3 . Here the THF ring bears two bulky substituents on the same side of the ring, thus the possibility of the existence of different conformations should be taken into account. Two different conformations were considered, that is ${ }^{4} E$ and ${ }^{3} E$, in which the $\mathrm{CH}_{2} \mathrm{Cl}$ or $\mathrm{CH}_{3}$ group is in the pseudo-equatorial orientation, respectively (Fig. 7). Both of these conformations hold their two bulky groups away from one another, thus avoiding steric interactions between them. Moreover, conformations are also free of torsion interactions since none of the substituents are in an eclipsed position. For the separate chloride, according to B3LYP, the ${ }^{4} E$ conformation has the lower energy although the difference between these two conformations is only $0.7 \mathrm{kcal} \mathrm{mol}^{-1}$.

Also in the reactant complex the ${ }^{4} E$ conformation appeared to be more stable, and again the energy difference is very small $\left(0.7 \mathrm{kcal} \mathrm{mol}^{-1}\right)$. In the transition state, however, the THF ring adopts the ${ }^{3} E$ conformation $\left(P=15^{\circ}, \phi_{\mathrm{m}}=38^{\circ}\right)$, in which the $\mathrm{C} 1$ atom is moved far away from the ring $\left(\chi_{1}=-158^{\circ}\right.$, Table 2$)$. Surprisingly, a completely different conformation of the THF ring is found for the ion pair. Here the ${ }^{0} E$ THF ring shape appeared to be preferred, regardless of the starting conformation taken to optimization. In this conformation both $\mathrm{CH}_{2} \mathrm{Cl}$ and $\mathrm{CH}_{3}$ are moved away at the same time thus avoiding the steric hindrance between these groups. However, this conformation suffers the torsion interaction occurring between vicinal hydrogen atoms at $\mathrm{C} 3$ and $\mathrm{C} 4$. Another surprising thing is that this conformation is not preferred in the free cation, where the ${ }^{3} T_{2}$ one is observed (Table 2).

There are also two non-hydrogen groups attached to the THF ring in reaction 4; however, in this case these groups are much different. The chloromethyl group, having a bigger effective size, was expected to locate in a pseudo-equatorial position. To confirm this statement two conformations were prepared, i.e., one with $\mathrm{CH}_{2} \mathrm{Cl}$ in pseudo-equatorial orientation and $\mathrm{OCH}_{3}$ in the pseudo-axial position $\left(E_{4}\right)$, and the other with the opposite spatial arrangement of these groups $\left(E_{3}\right)$. While the former conformation appeared to be stable in starting form, the latter one changed to ${ }^{2} E$ conformation 


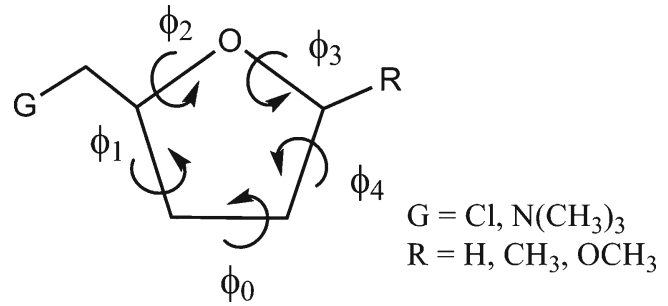

Fig. 6 Definition of the endocyclic torsion angles $\phi_{0}-\phi_{4}$

during optimization (Fig. 7). According to B3LYP/6-31+G** level, the $E_{4}$ conformer is more stable by about $0.9 \mathrm{kcal} \mathrm{mol}^{-1}$. With one exception the $E_{4}$ conformation is found to be preferred in all the stationary points of reaction 4 . The THF ring adopts a slightly different conformation $\left({ }^{3} T_{4}\right)$ in the transition state geometry only.

\section{Energy and geometry}

The results of the B3LYP/6-31+G** calculations for reactions 2, 3 and $\mathbf{4}$ are presented in Table 3. Optimized geometries together with selected bond distances, valence angles and relative energies corresponding to all the stationary points along the reaction pathway are presented in Fig. 8 . The relative energies refer to the sum of the separate reactant energies. The energy profiles for the reactions studied are illustrated in Fig. 9.
According to B3LYP functional, the formation of a reactant complex from individual species occurs with a slight reduction in energy $\left(\Delta E \sim-1.3 \mathrm{kcal} \mathrm{mol}^{-1}\right)$ for all the reactions studied (Table 3, Fig. 8). Similar values of the complexation energy, with one exception, were observed for reactions between mesylate derivatives and trimethylamine [24]. The above-mentioned exception concerns reaction $\mathbf{4}$, for which the complexation process was associated with an increase in energy (about $3 \mathrm{kcal} \mathrm{mol}^{-1}$ ). This increase in energy was attributed to the change in the spatial disposition of the metoxyl group from $-s c$ to $a p$ forced by the approach of trimethylamine to the reaction center carbon atom Fig. 7 . Currently such a conformational change is not observed and quite a typical energy value for the complexation is found. The Gibbs free energy predicts the complexation process to be unfavorable $\left(7.4 \mathrm{kcal} \mathrm{mol}^{-1}\right.$ on average) in all cases. The small value of the complexation energy indicates that the interaction between the constituents of the reaction complex is relatively weak. The slightly stronger intermolecular interaction occurs between mesylate and ammonia [27], which can be related to the type of intermolecular interactions between the constituents of the reactant complex. Presumably a typical S-O $\cdots \mathrm{H}-\mathrm{N}$ hydrogen bond stabilizes the reactant complex better than an atypical $\mathrm{S}-\mathrm{O} \cdots \mathrm{H}-\mathrm{C}$ hydrogen bond interaction [45], which was found for the reactions with trimethylamine.

Table 2 Selected torsion angles and calculated values of the pseudorotational phase angle $(P)$ and of the puckering amplitude $\left(\phi_{\mathrm{m}}\right)$ of the THF ring for conversions 2-4

\begin{tabular}{|c|c|c|c|c|c|c|c|c|c|c|}
\hline & & $P$ & $\phi_{\mathrm{m}}$ & $\phi_{0}$ & $\phi_{1}$ & $\phi_{2}$ & $\phi_{3}$ & $\phi_{4}$ & $\chi_{1}$ & $\chi_{2}$ \\
\hline \multicolumn{11}{|c|}{ Reaction 2} \\
\hline $\mathrm{R}$ & $E_{4} /{ }^{3} T_{4}$ & 352 & 36 & 36.0 & -27.2 & 6.8 & 16.8 & -33.0 & -145.2 & - \\
\hline $\mathrm{RC}$ & $E_{4} /{ }^{3} T_{4}$ & 351 & 36 & 36.1 & -27.0 & 6.3 & 17.4 & -33.4 & -145.4 & - \\
\hline $\mathrm{TS}$ & ${ }^{5} E$ & 310 & 37 & 23.9 & -4.1 & -19.2 & 34.9 & -36.0 & -128.7 & - \\
\hline IP & ${ }^{3} E$ & 15 & 37 & 35.7 & -35.3 & 21.0 & 2.4 & -24.5 & -157.3 & - \\
\hline $\mathrm{P}$ & ${ }^{3} E$ & 11 & 37 & 35.9 & -34.1 & 18.8 & 4.7 & -26.0 & -155.0 & - \\
\hline \multicolumn{11}{|c|}{ Reaction 3} \\
\hline $\mathrm{R}$ & ${ }^{4} E$ & 153 & 36 & -32.5 & 17.4 & 5.8 & -26.9 & 36.5 & -99.3 & 156.5 \\
\hline $\mathrm{RC}$ & ${ }^{4} E$ & 22 & 36 & -32.5 & 17.1 & 6.4 & -27.5 & 36.9 & -97.1 & 156.4 \\
\hline $\mathrm{TS}$ & ${ }^{3} E$ & 15 & 38 & 37.1 & -36.6 & 22.1 & 1.9 & -25.5 & -158.5 & 94.9 \\
\hline IP & ${ }^{o} E$ & 94 & -41 & -2.9 & -21.0 & 38.6 & -40.2 & 25.5 & -142.8 & 145.6 \\
\hline $\mathrm{P}$ & ${ }^{3} T_{2}$ & 33 & 37 & 31.1 & -37.3 & 29.6 & -9.1 & -14.9 & -157.5 & 104.6 \\
\hline \multicolumn{11}{|c|}{ Reaction 4} \\
\hline $\mathrm{R}$ & $E_{4}$ & 338 & 36 & 33.3 & -20.0 & -2.3 & 24.1 & -35.7 & -138.7 & 84.6 \\
\hline $\mathrm{RC}$ & $E_{4}$ & 339 & 36 & 33.7 & -20.8 & -1.3 & 23.3 & -35.4 & -139.8 & 84.9 \\
\hline $\mathrm{TS}$ & ${ }^{3} T_{4}$ & 359 & 39 & 39.2 & -31.9 & 12.0 & 13.4 & -33.1 & -155.0 & 86.9 \\
\hline IP & $E_{4}$ & 351 & 36 & 35.9 & -26.7 & 6.5 & 16.9 & -33.1 & -149.8 & 86.8 \\
\hline $\mathrm{P}$ & $E_{4}$ & 344 & 37 & 35.6 & -23.8 & 1.9 & 21.2 & -35.4 & -145.7 & 83.7 \\
\hline
\end{tabular}

Definition of the torsion angles: $\phi_{0}-\mathrm{C} 5-\mathrm{C} 4-\mathrm{C} 3-\mathrm{C} 2 ; \phi_{1}-\mathrm{C} 4-\mathrm{C} 3-\mathrm{C} 2-\mathrm{O} 2 ; \phi_{2}-\mathrm{C} 3-\mathrm{C} 2-\mathrm{O} 2-\mathrm{C} 5 ; \phi_{3}-\mathrm{C} 2-\mathrm{O} 2-\mathrm{C} 5-\mathrm{C} 4 ; \phi_{4}-\mathrm{O} 2-\mathrm{C} 5-\mathrm{C} 4-\mathrm{C} 3$; $\mathrm{X}_{1}-\mathrm{C} 1-\mathrm{C} 2-\mathrm{C} 3-\mathrm{C} 4 ; \mathrm{x}_{2}-\mathrm{R}-\mathrm{C} 5-\mathrm{C} 4-\mathrm{C} 3$, where R represents the substituent attached to $\mathrm{C} 5$ 
Fig. 7 Two low energy conformers found for the free reactant in reactions 3 and 4 . Relative energies are given in brackets

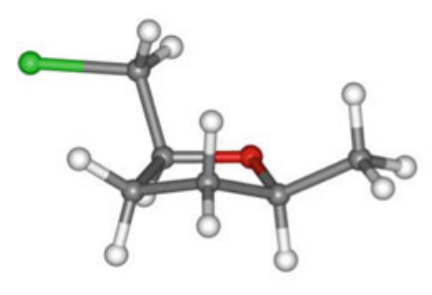

${ }^{4} E\left(0.0 \mathrm{kcal} \mathrm{mol}^{-1}\right)$

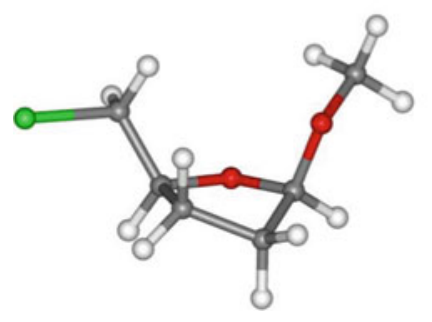

$E_{4}\left(0.0 \mathrm{kcal} \mathrm{mol}^{-1}\right)$
Reaction 3

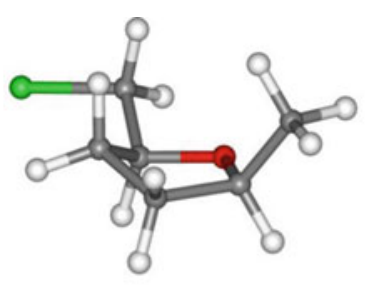

${ }^{3} E\left(0.7 \mathrm{kcal} \mathrm{mol}^{-1}\right)$

Reaction 4

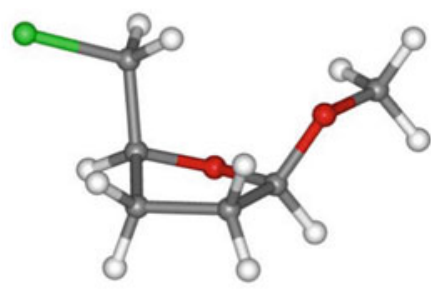

${ }^{2} E\left(0.9 \mathrm{kcal} \mathrm{mol}^{-1}\right)$
The next stationary point on the potential energy curve (Fig. 9) corresponds to the transition state. The geometry parameters characterizing calculated TSs are given in Table 3 and in Fig. 8. The $\mathrm{C} \cdots \mathrm{Cl}$ and $\mathrm{C} \cdots \mathrm{N}$ distances are greater than those found for reaction $\mathbf{1}$. On the other hand, these distances are roughly the same in reactions $\mathbf{2 , 3}$ and $\mathbf{4}$. Another geometrical difference between transition states for reaction 1 and the other three reactions concerns the $\mathrm{Cl} \cdots \mathrm{C} \cdots \mathrm{N}$ valence angle. While in the case of reaction $\mathbf{1}$ these three atoms lie ideally in a straight line, the TSs calculated for reactions $\mathbf{2}$, 3 and $\mathbf{4}$ are bent (Table 3, Fig. 8), which is the result of branching close to the reaction center.

The approach of the trimethylamine molecule to the $\mathrm{C} 1$ atom induces considerable conformational changes within the mesylate derivative. First, the conformational change of the THF ring is observed during the conversion of the reactant complex into the transition state for reactions $2\left(E_{4}{ }^{3} T_{4} \rightarrow{ }^{5} E\right)$ and $\mathbf{3}\left({ }^{4} E \rightarrow{ }^{3} E\right)$. In the case of reaction 4 the THF ring changes are rather insignificant $\left(E_{4} \rightarrow{ }^{3} T_{4}\right)$. Next, an important variation of the $\mathrm{Cl}-\mathrm{C} 1-\mathrm{C} 2-\mathrm{C} 3$ torsion angle can be noticed (A, Table 3 ). In reactant complexes this angle is about $-67^{\circ}$, whereas in the transition state it takes values of $40.2^{\circ},-4.7^{\circ}$ and $-7.9^{\circ}$ for reactions $\mathbf{2}, \mathbf{3}$ and $\mathbf{4}$, respectively. In the case of reaction $\mathbf{2}$ the rotation about the $\mathrm{C} 1-\mathrm{C} 2$ bond results in placing the leaving group above the THF ring. In the two remaining cases breaking the $\mathrm{C} 1-\mathrm{Cl}$ bond is almost in an eclipse position with respect to the $\mathrm{C} 2-\mathrm{C} 3$ bond.

The value of the $\mathrm{H}-\mathrm{C}-\mathrm{X}$ valence angle is frequently used to distinguish whether the transition state is an early or late one [8]. Indeed, we were able to decide about the character of the transition state for reaction $\mathbf{1}$ where atoms $\mathrm{N}, \mathrm{C} 1$ and $\mathrm{Cl}$ were in a straight line. However, this angle does not give an answer to this question when the transition state geometry is not linear. In such a situation we prefer to judge this dilemma based on the inspection of the deformation angle (B, Table 2, Fig. 3). These angles (Table 2) clearly show, based on the convention accepted in this paper, the late transition states for all three reactions studied in the gas phase.

The computed relative energy values matching the transition states with respect to the separated reactants are given in Table 3 and in Fig. 8, and the activation barriers relating to the reactant complexes are listed in Table 4 . The calculated barriers for reactions 2-4 are higher (4 $\mathrm{kcal} \mathrm{mol}^{-1}$ or more) than that found for reaction $\mathbf{1}$, unquestionably because of the branching occurring close to the reaction center. Furthermore, the branching at the $\mathrm{C} 5$ carbon atom is also the source of barrier height differentiation. Comparing these three reactions one can see that the lowest barrier is for reaction $\mathbf{2}$ and the highest is for reaction 4. It seems that the lack of the substituent bounded to the $\mathrm{C} 5$ carbon atom facilitates the rotation about the $\mathrm{C} 1-\mathrm{C} 2$ bond. As was stated earlier, due to this rotation the chloride atom moves above the THF ring, but also the partially bounded trimethylamine molecule moves to a less crowed position, which results in reduction of the barrier height. In the case of reactions $\mathbf{3}$ and $\mathbf{4}$ the substituent attached to the $\mathrm{C} 5$ atom makes impossible the rotation around the $\mathrm{C} 1-\mathrm{C} 2$ bond. Consequently, the nucleophile cannot move to a less crowded position, and thus the barrier height decrease is not observed here. In reaction $\mathbf{4}$, as well as the steric hindrance, possibly the electrostatic repulsion between the partially released chloride atom and glycosidic oxygen atom (O5) also blocks the rotation about the $\mathrm{C} 1-\mathrm{C} 2$ bond, hence increasing the barrier with respect to reaction 3 . 


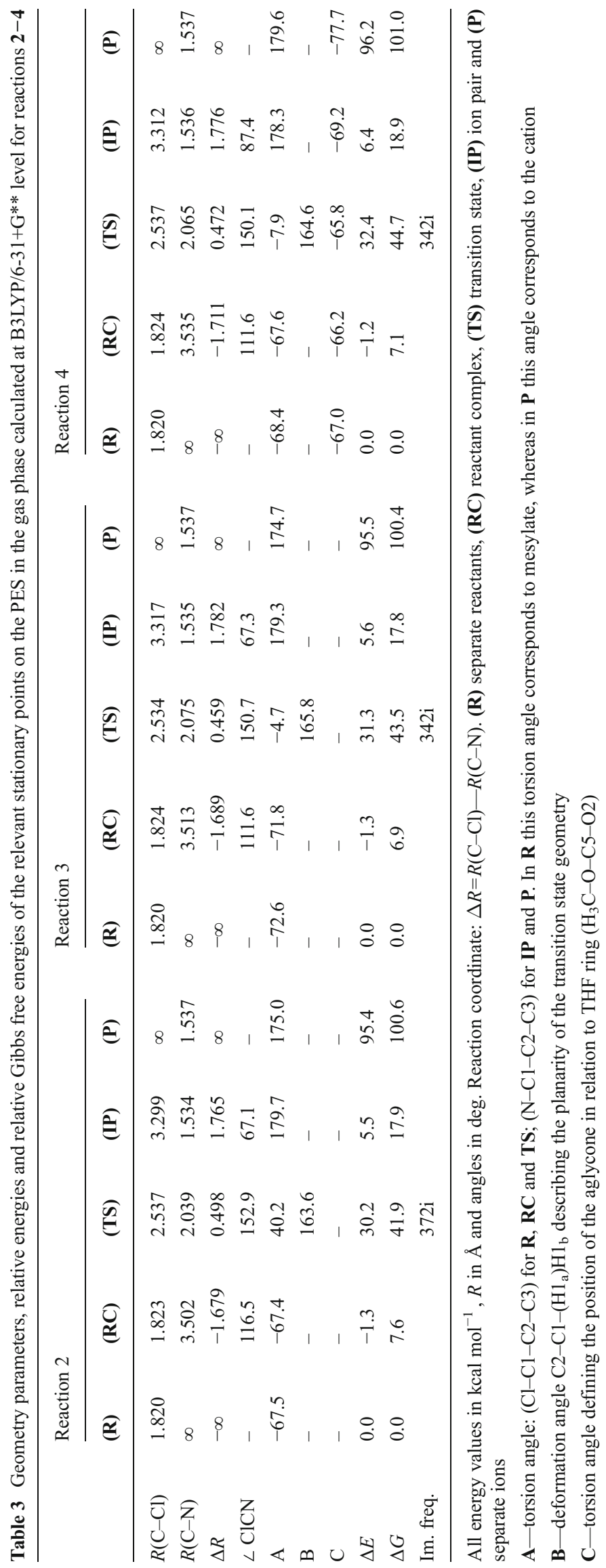



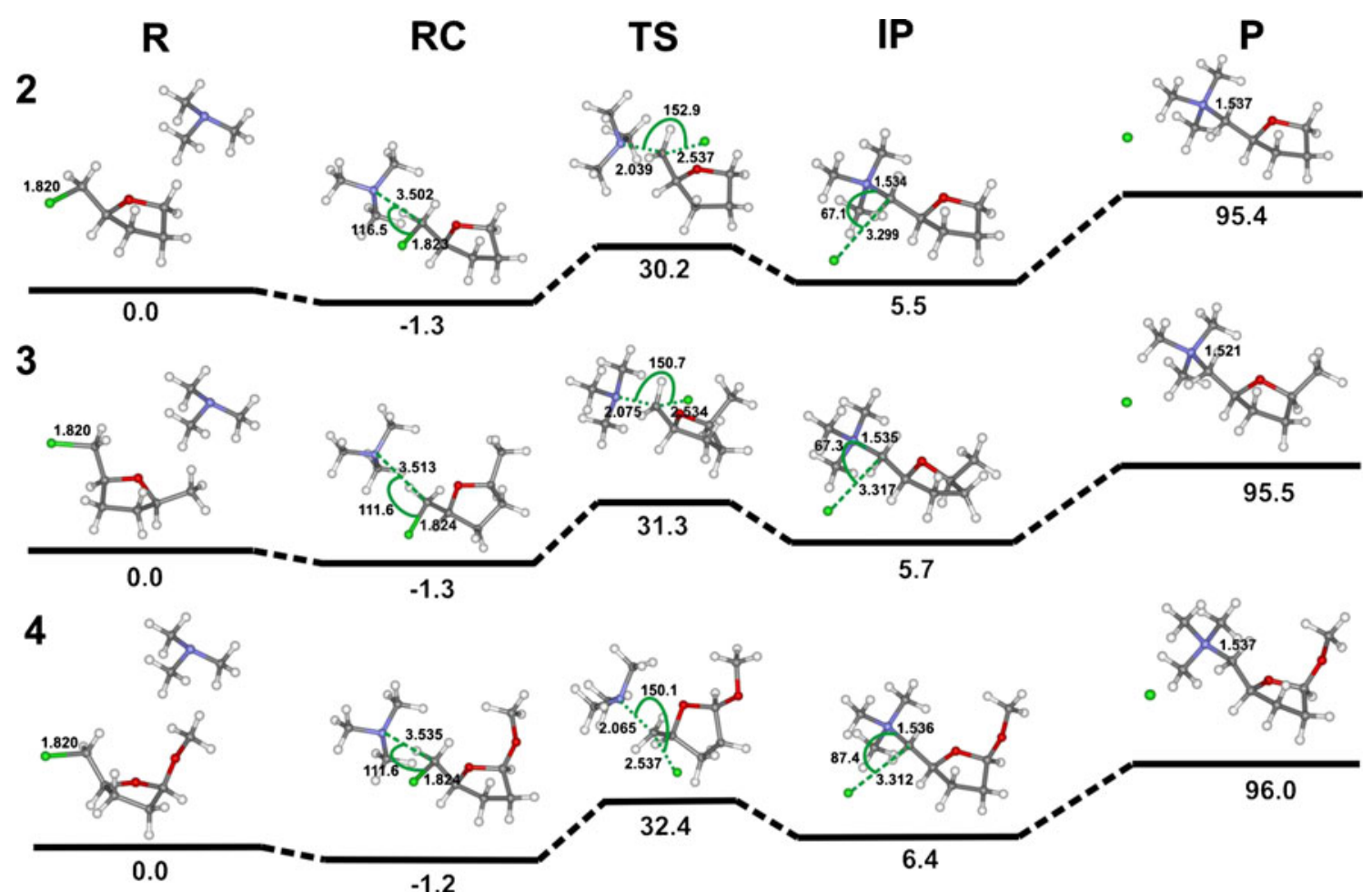

$-1.3$

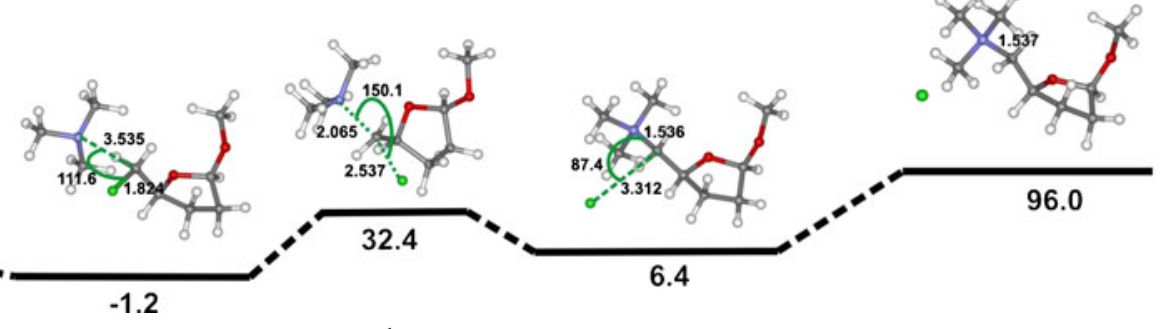

Fig. 8 Geometries of the critical points and relative energies $\left(\mathrm{kcal} \mathrm{mol}^{-1}\right)$ computed at the $\mathrm{B} 3 \mathrm{LYP} / 6-31+\mathrm{G}^{* *}$ level for reactions $\mathbf{2}-\mathbf{4}$ in the gas phase. Selected distances in $\AA$, and valence angles in degrees

MPW1K functional predicts the barriers to be higher by about $4 \mathrm{kcal} \mathrm{mol}^{-1}$ (Table 4). According to both B3LYP/6$31+\mathrm{G}^{* *}$ and MPW1K/6-31+G** level calculations, the barriers obtained for the reactions in which a chloride atom is substituted by the tertiary amine are higher (about $3 \mathrm{kcal}$ $\mathrm{mol}^{-1}$ ) than those for the analogues reactions described elsewhere [24]. The data presented in Table 4 show that the activation barriers calculated at the B3LYP/6-31+G** and B3LYP/6-311++G** theory levels are identical therefore the extending of the basis set is pointless in this case.

The $\Delta E$ predicts that the conversion of the reactant complexes into respective ion pairs is accompanied by an energy increase (about $7 \mathrm{kcal} \mathrm{mol}^{-1}$ ) in the gas phase. This is in contrast to our previous studies in which the ion pairs had lower energy than the respective reactant complexes [24-27].

As in previous papers, the separation of the constituents of the ion pair was strongly endergonic in the gas phase. Comparing the results obtained for the reactions of trimethylamine with respective mesylates and chlorides one can notice that the final step of the reaction is even more difficult for the latter, which is possibly the result of poorer negative charge delocalization in chloride anion [24].

\section{Solvent effects calculated for reactions $\mathbf{2}, \mathbf{3}$ and $\mathbf{4}$}

To study the solvents' effects on the reactions under scrutiny a Tomasi's polarizable continuum model (PCM) was used [38]. The PCM model permits the self-consistent computation of free energies of solvation, including polarized solute/solvent interactions and non-electrostatic terms in the Hamiltonian. On the other hand, it should be emphasized that reaction field models are incapable of modeling specific (short-range) solute/solvent interactions, i.e., those occurring in the first solvation sphere. Thus, the conclusions drawn based on the

Table 4 Activation energies calculated for reactions 2, 3 and 4 in the gas phase. All energy values in kcal mol ${ }^{-1}$

\begin{tabular}{|c|c|c|c|c|c|c|}
\hline & \multicolumn{2}{|c|}{ B3LYP/6-31+G** } & \multicolumn{2}{|c|}{ B3LYP/6-311++G** } & \multicolumn{2}{|c|}{ MPW1K/6-31+G** } \\
\hline & $\Delta E^{\ddagger}$ & $\Delta G^{\ddagger}$ & $\Delta E^{\ddagger}$ & $\Delta G^{\ddagger}$ & $\Delta E^{\ddagger}$ & $\Delta G^{\sharp}$ \\
\hline Reaction 2 & 31.5 & 34.3 & 31.5 & 34.1 & 35.3 & 38.5 \\
\hline Reaction 3 & 32.6 & 36.7 & 32.6 & 36.6 & 36.7 & 40.6 \\
\hline Reaction 4 & 33.6 & 37.6 & 33.7 & 37.8 & 37.9 & 42.6 \\
\hline
\end{tabular}

* relates to activation parameters of the reaction 
calculations where such interactions occur should be interpreted with care. Despite the limitations of the implicit solvent models, this approach was successfully applied to elucidate many chemical problems. It is recognized that PCM operates better in aprotic solvents; however, it has been used to predict the solvation effect in protic solvents, too $[17,46]$.

In our previous paper [26] it was shown that almost the entire solvent effect is achieved after single point PCM calculations, and no significant energy changes were observed during the optimization in water. Moreover, it was shown that the TS geometry changes were not so profound as those experienced with the classical Menshutkin reaction [8, 47]. In the course of our studies we found that the energy changes accompanying the reactions conducted in ethanol and water are roughly the same; therefore, the optimization in two solvents, i.e., chloroform and water was carried out. The results of calculations in chloroform and in water are listed in Table 5, and the energy diagrams are presented in Fig. 9.

The energy diagrams show roughly the same stability of reactant complexes in the gas phase and in both solvents (Fig. 9). In chloroform the complexation occurs with an energy reduction of about $1 \mathrm{kcal} \mathrm{mol}^{-1}\left(U_{0}\right)$ and an increase in the Gibbs free energy ( $8 \mathrm{kcal} \mathrm{mol}^{-1}$, Table 5). Also, no significant geometry changes are observed for reactant complexes after optimization in both solvents. This suggests that in the case of the reactions under consideration the complexation process is almost independent of the environment in which it occurs, according to PCM/B3LYP/6-31+G** calculations.

The geometry changes that occur in the transition state upon the optimization in solvents, particularly in water (Table 5), are significant. The THF ring conformation changes are illustrated in Fig. 10. In the case of reaction 2 the THF ring smoothly turns to conformations neighboring in the pseudorotational circle, on going from the gas phase, through chloroform to water. In the gas phase the THF ring has ${ }^{5} E$ and converts into ${ }^{5} T_{4}$ in chloroform to finally adopt the $E_{4}$ conformation in water $\left({ }^{5} E \rightarrow{ }^{5} T_{4} \rightarrow E_{4}\right)$. The same $\left({ }^{3} E\right)$ conformation is found for reaction $\mathbf{3}$ in the gas phase and in chloroform, whereas the THF ring conformation changed into the conformation more distant in the pseudorotational circle during the optimization in water, $\left({ }^{3} E \rightarrow E_{5}\right)$. Such a significant variation of the THF ring shape in the case of reaction 3 taking place in water gives rise to the possibility of rotation about the $\mathrm{C} 1-\mathrm{C} 2$ bond (torsion angle $\mathbf{A}$, Table 5). As a consequence, the leaving group, located almost exactly above the C2-C3 bond (torsion angle $\mathbf{A}$, Table 3 ) in the gas phase, moved above the THF ring, as in reaction 2 . In contrast to reactions $\mathbf{2}$ and $\mathbf{3}$, in the case of reaction $\mathbf{4}$ the THF ring did not substantially change its conformation in solvents with respect to that in a vacuum $\left({ }^{3} T_{4} \rightarrow E_{4} \rightarrow E_{4}\right)$. Therefore, the rotation about the $\mathrm{Cl}-\mathrm{C} 1-\mathrm{C} 2-\mathrm{C} 3$ torsion angle is not feasible here due to the proximity of the $\mathrm{OCH}_{3}$ group.

Furthermore, the $\mathrm{C} \cdots \mathrm{Cl}$ and $\mathrm{C} \cdots \mathrm{N}$ distances changed in the transition states geometry during optimization in solvents. The $\mathrm{C} \cdots \mathrm{N}$ distance elongates, whereas the $\mathrm{C} \cdots \mathrm{Cl}$ one shortens, when the reaction takes place in the condensed phase. In chloroform the $\mathrm{C} \cdots \mathrm{N}$ distance increased and the $\mathrm{C} \cdots \mathrm{Cl}$ distance decreased by about $5 \%$ and $2 \%$ on average, respectively, in relation to the values found in the gas phase. In water the changes of these distances are approximately twice as big as in chloroform. Nevertheless, the observed distance changes are not as profound as in the case of reaction $\mathbf{1}$.

Another geometry parameter concerning the transition state that changed during the optimization in solvents is the deformation angle (B, Table 5). Values of this angle found in water clearly show that ligands attached to the $\mathrm{C} 1$ atom are almost planar, therefore indicating that the transition states are nearly half way between the reactants and products, whereas they are more product-like in the gas phase (Table 3). All these described changes prove that the transition states have shifted toward an earlier stage of the reaction in both solvents with respect to the gas phase, which is typical for the Menshutkin reaction taking place in the condensed phase.

The B3LYP/6-31+G** level barriers calculated in solvents are significantly lower than those calculated for the gas phase. For reaction 2 taking place in chloroform, the barrier $\left(\Delta U_{0}^{\ddagger}\right)$ is about $5 \mathrm{kcal} \mathrm{mol}^{-1}$ lower, whereas in water it is approximately $10 \mathrm{kcal} \mathrm{mol}^{-1}$ less (Tables 4 and 5).
Reaction 2

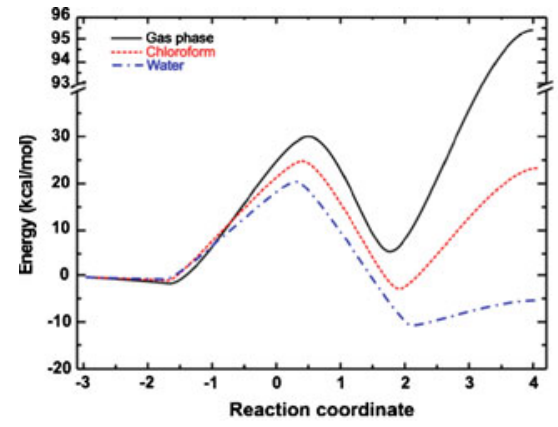

Reaction 3

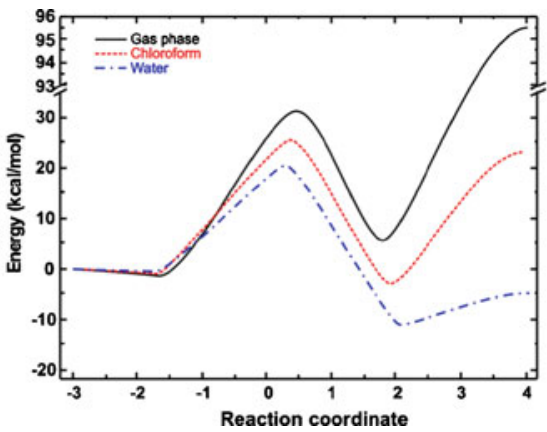

Reaction 4

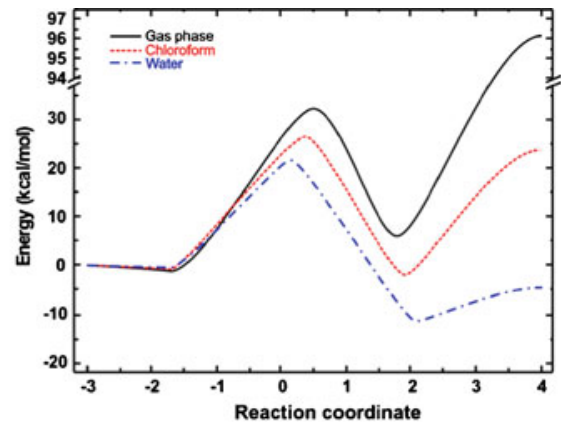

Fig. 9 Potential energy curves for reactions 2-4 in the gas phase, chloroform and water, calculated at the B3LYP/6-31+G** level 


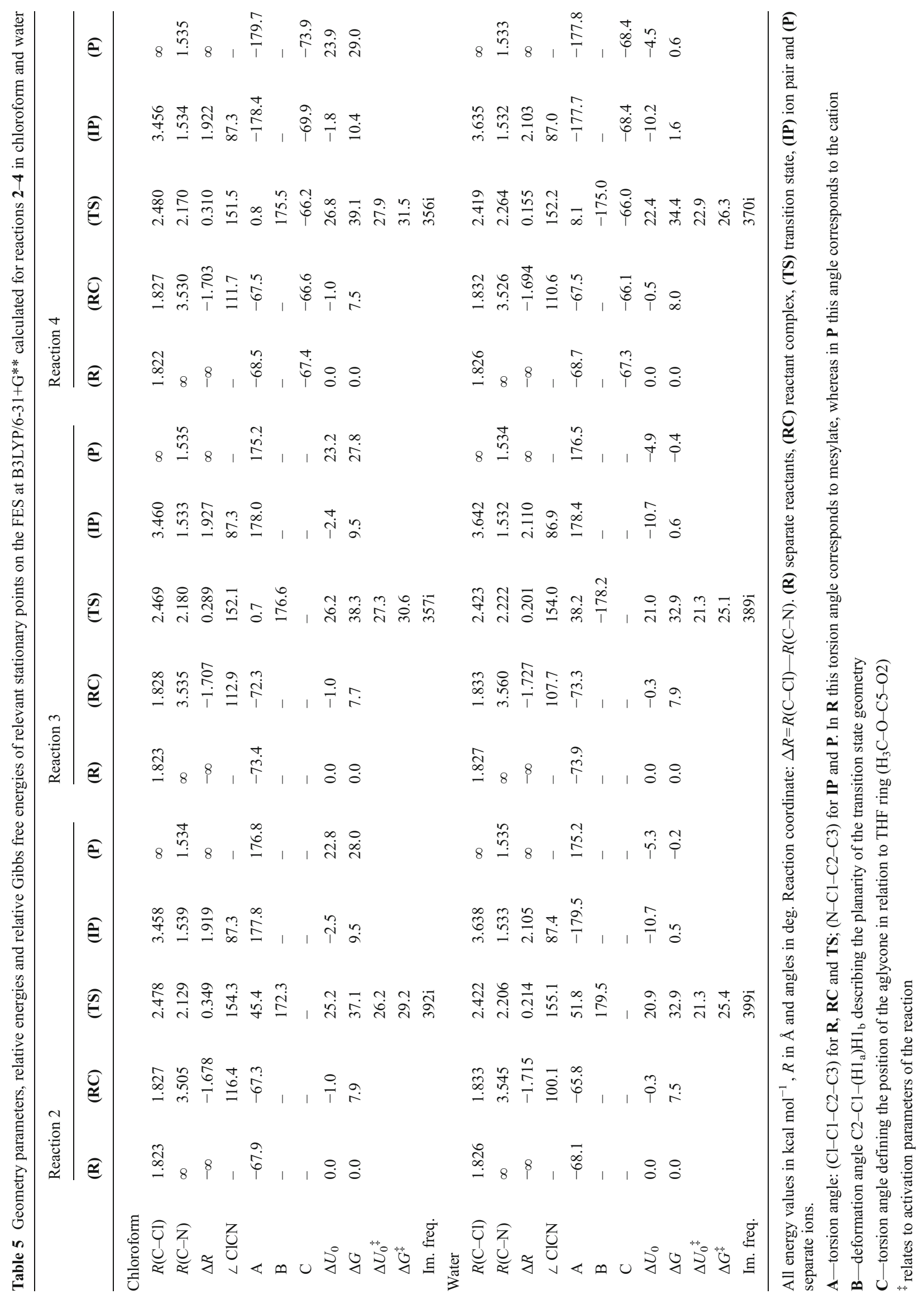


Fig. 10 Comparison of transition state geometries. Selected distances in $\AA$, and valence angles in degrees

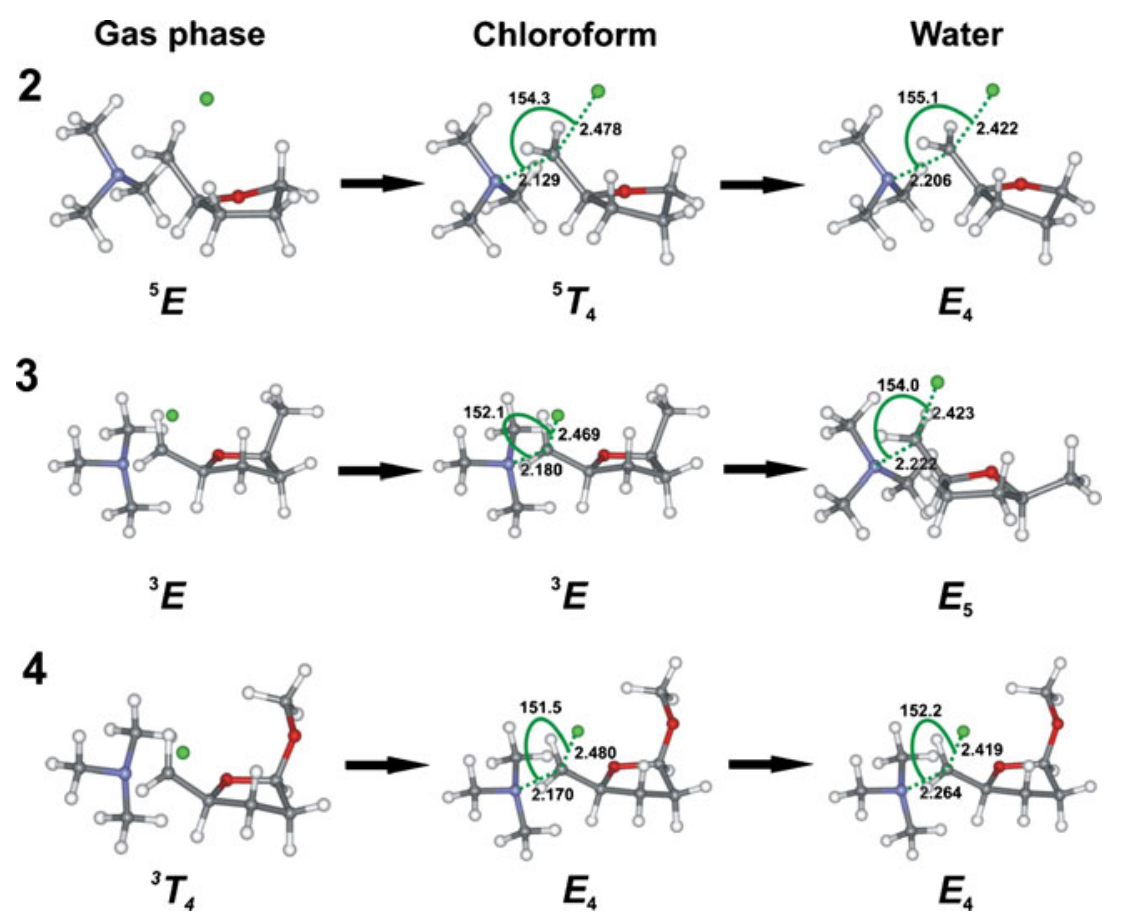

Similar energy barrier changes are observed for two other reactions.

Evidently the bifurcation at the $\mathrm{C} 2$ atom leads to significant energy barrier increases. In the case of reaction $\mathbf{2}$, occurring in chloroform, the barrier is by about $7 \mathrm{kcal} \mathrm{mol}^{-1}$ higher than that for reaction 1 . The barriers are even higher for the other two reactions. A certain differentiation of the energy barriers can be observed depending on the kind of substituent bonded at the $\mathrm{C} 5$ carbon atom, being in cis orientation with respect to the reaction center carbon atom $(\mathrm{C} 1)$. In chloroform, the lowest barrier is found for reaction 2 (with a hydrogen at the $\mathrm{C} 5$ atom), whereas for reaction 4 (the $\mathrm{OCH}_{3}$ group at the $\mathrm{C} 5$ atom) the barrier is highest. In turn, the barriers for reactions 2 and $\mathbf{3}$ are roughly the same in water, whereas for reaction $\mathbf{4}$ it is about $1 \mathrm{kcal} \mathrm{mol}^{-1}$ higher. Presumably the THF ring conformation change followed by the rotation about the $\mathrm{C} 1-\mathrm{C} 2$ bond are the source of the identical barriers for reactions $\mathbf{2}$ and 3 observed in water. Neither in the gas phase nor in solvents such geometrical changes are observed for reaction 4; thus, both the leaving group and attacking nucleophile are in unfavorable positions. Although the differences between the barriers found for reactions $\mathbf{2 , 3}$ and $\mathbf{4}$ are rather small, such an order of reactivity, i.e., $\mathbf{2}>\mathbf{3}>\mathbf{4}$, is repeatedly observed in our studies [24-27].

The bimolecular conversion of reactant complexes into ion pairs is accompanied by a slight energy decrease $\left(U_{0}\right.$ reduced by about $1 \mathrm{kcal} \mathrm{mol}^{-1}$ ), but Gibbs free energy suggests that this step of the reaction is somewhat unfavorable in chloroform (Table 5). In water, however, both $\Delta U_{0}$ and $\Delta G$ indicate that the ion pair formation should be favorable. It should be emphasized here that the ion pair was predicted to be unstable in very polar solvents and its dissociation occurs spontaneously [8]. In our studies the ion pair appeared to be a real minimum on the free energy surface.

The final step of the reaction, i.e., separation of the constituents of the ion pair, is strongly unfavorable in chloroform; however, in water the Gibbs free energy difference between the separated reactants and separated ions appeared to be close to zero.

\section{Conclusions}

DFT studies on quaternary ammonium salt formation according to a Menshutkin reaction, occurring between trimethylamine and four chloride derivatives were carried out in this work.

Conducted calculations indicate that the overall process is highly unfavorable in the gas phase and in chloroform, but in water the sum of the energies of individual ions are less $\left(\Delta U_{0}\right)$ than that of the separate reactants, or roughly the same $(\Delta G)$.

Ion pairs are less stable than the respective reactant complexes in the gas phase whereas in both solvents the stability order is reversed.

The gas phase energy barriers for reactions $\mathbf{2}-\mathbf{4}$ are higher than that found for reaction $\mathbf{1}$, unquestionably because of the branching occurring close to the reaction center. Moreover, the substitution at the $\mathrm{C} 5$ carbon atom also differentiates the barrier height. The lowest barrier is found for reaction 2 (unsubstituted at the $\mathrm{C} 5$ atom) whereas for reaction 4 (with 
$\mathrm{OCH}_{3}$ group bounded to the $\mathrm{C} 5$ atom) the barrier is highest. The barriers obtained for reactions $\mathbf{2}$ and $\mathbf{3}$ in water appeared to be very close to one another, whereas the highest barrier is found for reaction 4 .

It has been shown that extending the basis set is pointless in our studies as the barriers found at the two theory levels appeared to be roughly the same. The MPW $1 \mathrm{~K} / 6-31+\mathrm{G}^{* *}$ level predicts the barriers to be higher than those from B3LYP calculations. However, the trend of the reactivity is the same, according to both functionals used.

The early/late character of the transition state geometry correlates well with the environment polarity. A more product-like transition state is found in the gas phase whereas it becomes reactant-like in water.

Significant geometry changes are observed along the reaction pathway. The THF ring conformational variation took place for reactions $\mathbf{2}$ and $\mathbf{3}$ during optimization in the gas phase. In contrast, the THF was practically unchanged along the reaction pathway for reaction 4 . Moreover, the $\mathrm{Cl}-\mathrm{C} 1-\mathrm{C} 2-\mathrm{C} 3$ torsion angle changes on going from the reactant complex to transition state. In reactant complexes this angle is in characteristic $-s c$ conformation, whereas in transition states breaking $\mathrm{C}-\mathrm{Cl}$ bond is almost in an ecliptic arrangement with reference to the $\mathrm{C} 2-\mathrm{C} 3$ bond for reactions 3 and $\mathbf{4}$. In turn, a $-s c \rightarrow s c$ conformational change is observed for reaction $\mathbf{2}$, which results in the leaving group moving above the THF ring.

Further significant geometric changes took place during the optimization in solvents, particularly in water. For reaction 2 the THF ring passed to the conformation neighboring in the pseudorotational circle, $\left({ }^{5} E \rightarrow E_{4}\right)$ in the transition state geometry. In turn, for reaction $\mathbf{3}$ the greater conformational change of the THF ring occurred upon optimization in water $\left({ }^{3} E \rightarrow E_{5}\right)$.

In general, the THF ring shape is rather not prone to changes in the case of reaction 4 . It owes its rigidity to the substituents attached to this ring. The chloromethyl group (as is the $\mathrm{N}, \mathrm{N}, \mathrm{N}$-trimethylammoniummethyl group found on product side) is effectively greater than the $\mathrm{OCH}_{3}$ one, i.e., it causes stronger steric strains, and therefore it prefers positions more distant (pseudo-equatorial) from the other substituents. On the other hand, it seems that $\mathrm{OCH}_{3}$ prefers axial-like orientation. The THF ring is more flexible in the case of reaction 2 ; however, the pseudorotational freedom of this ring is limited to conformations in which the chloromethyl group (and $N, N, N$-trimethylammoniummethyl group) is in a pseudo-equatorial position. A very different situation is seen for reaction $\mathbf{3}$, where two non-hydrogen groups are roughly the same in terms of conformational preference. Thus, different conformations are adopted by the THF ring along the reaction pathway. Moreover, the different conformations found in the ion pair and in free cations indicate that the preference of concrete conformation can be influenced by the intramolecular interactions.
Acknowledgments This work was supported by DS/530-8451D193-13. All DFT calculations were carried out using the resources of the Informatics Centre of the Metropolitan Academic Network in Gdańsk (CI TASK).

Open Access This article is distributed under the terms of the Creative Commons Attribution License which permits any use, distribution, and reproduction in any medium, provided the original author(s) and the source are credited.

\section{References}

1. Menschutkin N (1890) Z Phys Chem 5:589-601

2. Fischer E, Raske K (1910) Chem Ber 43:1750-1753

3. Pellowska-Januszek L, Dmochowska B, Skorupa E, Chojnacki J, Wojnowski W, Wiśniewski A (2004) Carbohydr Res 339:15371544

4. Skorupa E, Dmochowska B, Pellowska-Januszek L, Wojnowski W, Chojnacki J, Wiśniewski A (2004) Carbohydr Res 339:2355-2362

5. Dmochowska B, Skorupa E, Pellowska-Januszek L, Czarkowska M, Sikorski A, Wiśniewski A (2006) Carbohydr Res 341:19161921

6. Dmochowska B, Skorupa E, Świtecka P, Sikorski A, Łacka I, Milewski S, Wiśniewski A (2009) J Carbohydr Chem 28:222-233

7. Mantell SJ, Ford PS, Watkin DJ, Fleet GWJ, Brown D (1993) Tetrahedron 49:3343-3358

8. Castejon H, Wiberg KB (1999) J Am Chem Soc 121:2139-2146

9. Viers JW, Schug JC, Stovall MD, Seeman JI (1984) J Comput Chem 5:598-605

10. Solà M, Lledós A, Duran M, Bertrán J, Abboud J-LM (1991) J Am Chem Soc 113:2873-2879

11. Gao J, Xia X (1993) J Am Chem Soc 115:9667-9675

12. Maran U, Pakkanen TA, Karelson M (1994) J Chem Soc Perkin Trans 2:2445-2452

13. Shaik S, Ioffe A, Reddy AC, Pross A (1994) J Am Chem Soc 116:262-273

14. Fradera X, Amat L, Torrent AM, Mestres J, Constans P, Besalú E, Martí J, Simon S, Lobato M, Oliva JM, Luis JM, Andrés M, Solà M, Carbó R, Duran M (1996) J Mol Struct (THEOCHEM) 371:171-183

15. Truong TN, Truong T-TT, Stefanovich EV (1997) J Chem Phys 107:1881-1889

16. Maran U, Karelson M, Pakkanen TA (1997) J Mol Struct (THEOCHEM) 397:263-272

17. Amovilli C, Mennucci B, Floris FM (1998) J Phys Chem B 102:3023-3028

18. Webb SP, Gordon MS (1999) J Phys Chem 103:1265-1273

19. Poater J, Solà M, Duran M, Fradera X (2001) J Phys Chem A 105:6249-6257

20. Acevedo O, Jorgensen WL (2010) J Phys Chem B 114:8425-8430

21. Melo A, Alfaia AJI, Reis JCR, Calado ART (2006) J Phys Chem B 110:1877-1888

22. Fábián A, Ruff F, Farkas Ö (2008) J Phys Org Chem 21:988-996

23. Bini R, Chiappe C, Pomelli CS, Parisi B (2009) J Org Chem 74:8522-8530

24. Nowacki A, Dmochowska B, Jączkowska E, Sikora K, Wiśniewski A (2011) Comput Theor Chem 973:53-61

25. Nowacki A, Dmochowska B, Sikora K, Madaj J, Wiśniewski A (2012) Comput Theor Chem 986:85-92

26. Nowacki A, Sikora K, Dmochowska B, Wiśniewski A (2012) Comput Theor Chem 1000:33-41

27. Nowacki A, Sikora K, Dmochowska B, Wiśniewski A (2013) J Mol Model 19:3015-3026 
28. Schaftenaar G, Noordik JH (2000) J Comput Aided Mol Des 14:123-134

29. Becke AD (1993) J Chem Phys 98:5648-5652

30. Lee C, Yang W, Parr RG (1988) Phys Rev B 37:785-789

31. Hehre WJ, Ditchfield R, Pople JA (1972) J Chem Phys 56:22572261

32. Clark T, Chandrasekhar J, Spitznagel GW, Schleyer P v R (1983) J Comput Chem 4:294-301

33. McLean AD, Chandler GS (1980) J Chem Phys 72:5639-5648

34. Krishnan R, Binkley JS, Seeger R, Pople JA (1980) J Chem Phys 72:650-654

35. Lynch BJ, Fast PL, Harris M, Truhlar DG (2000) J Phys Chem A 104:4811-4815

36. Lynch BJ, Truhlar DG (2001) J Phys Chem A 105:2936-2941

37. Zhao Y, Pu J, Lynch BJ, Thuhlar DG (2004) Phys Chem Chem Phys 6:673-676

38. Tomasi J, Persico M (1994) Chem Rev 94:2027-2094

39. Frisch MJ, Trucks GW, Schlegel HB, Scuseria GE, Robb MA, Cheeseman JR, Montgomery JA Jr, Vreven T, Kudin KN, Burant JC, Millam JM, Iyengar SS, Tomasi J, Barone V, Mennucci B, Cossi M, Scalmani G, Rega N, Petersson GA, Nakatsuji H, Hada M, Ehara M, Toyota K, Fukuda R, Hasegawa J, Ishida M, Nakajima T, Honda Y, Kitao O, Nakai H, Klene M, Li X, Knox JE, Hratchian
HP, Cross JB, Bakken V, Adamo C, Jaramillo J, Gomperts R, Stratmann RE, Yazyev O, Austin AJ, Cammi R, Pomelli C, Ochterski JW, Ayala PY, Morokuma K, Voth GA, Salvador P, Dannenberg JJ, Zakrzewski VG, Dapprich S, Daniels AD, Strain MC, Farkas O, Malick DK, Rabuck AD, Raghavachari K, Foresman JB, Ortiz JV, Cui Q, Baboul AG, Clifford S, Cioslowski J, Stefanov BB, Liu G, Liashenko A, Piskorz P, Komaromi I, Martin RL, Fox DJ, Keith T, Al-Laham MA, Peng CY, Nanayakkara A, Challacombe M, Gill PMW, Johnson B, Chen W, Wong MW, Gonzalez C, Pople JA (2004) Gaussian 03, Revision C.02. Gaussian, Inc, Wallingford, CT

40. Andersson MP, Uvdal P (2005) J Phys Chem A 109:2937-2941

41. Kim Y, Mohring JR, Truhlar DG (2010) J Am Chem Soc 132:11071-11082

42. Lias SG, Lieberman JF, Levin RD (1984) J Phys Chem Ref Data 13:695-808

43. Altona C, Sundaralingam M (1972) J Am Chem Soc 94:8205-8212

44. Houseknecht JB, Altona C, Hadad CM, Lowary TL (2002) J Org Chem 67:4647-4651

45. Koch U, Popelier PLA (1995) J Phys Chem 99:9747-9754

46. Martínez AG, Vilar ET, Barcina JO, de la Moya CS (2005) J Org Chem 70:10238-10246

47. Acevedo O, Jorgensen WL (2010) Acc Chem Res 43:142-151 